\title{
EL HOMBREAMERICANO
}

Julián Meza*

RESUMEN: El hombre americano busca sus orígenes, viaja, contempla, investiga. Mira pasar la Historia ante sus ojos, una historia intensamente mexicana, y recuerda con nostalgia el paso de dos mamuts por el estrecho de Bering...

পod

ABSTRACT: In search of his roots, the American man, travels, contemplates, and scrutinizes. He observes history passing by his eyes and nostalgically remembers the crossing of two mammoths through the Bering Strait...

PALABRAS CLAVE: hombre americano, conquista, independencia, revolución, modernidad. KEYWORDS: American man, conquest, independence, revolution, modern age.

RECEPCIÓN: 5 de noviembre de 2010.

APROBACIÓN: 5 de noviembre de 2010.

* Escritor. 
La reproducción total o parcial de este artículo se podrá hacer si el ITAM otorga la autorización previamente por escrito. 


\section{EL HOMBRE AMERICANO}

El hombre americano no entendía su propia historia. Cansado de escuchar las estupideces puestas en circulación por variados especialistas en el tema de las genealogías (antropólogos, historiadores, filósofos, etnógrafos, teólogos, mitógrafos, arqueólogos y economistas, entre otros), decidió remontar -junto con sus mujeres (apenas una docena) y sus hijos (muy numerosos)- el continente americano, desde la Patagonia hasta el extremo Norte y, esto es lo importante, desandando varios miles de años en el tiempo, con el propósito de atisbar en sus orígenes. No pretendía esclarecerlos porque sabía que en cuestión de genealogías nada se puede aclarar: siempre hay por ahí algún bastardo. Tras un prolongado esfuerzo de concentración en el que empeñó grandes dosis de ánimo y voluntad, llegó a un paisaje helado, propio de hace unos setenta mil años. Era, probablemente, lo que más tarde se llamaría estepa siberiana. Definitivamente había ido demasiado lejos en el tiempo, pues aún no había sido inventado el Jardín del Edén, en donde viviría la primera pareja de seres humanos, obra de una antropomórfica divinidad barbuda, que no se llamaba Zeus ni Jehová e ignoraba la existencia de lo que serían África, China y las Comores. Caminó lentamente en el tiempo y en el espacio hasta llegar a lo que, de tan angosto, se conocería después como estrecho de Bering, por donde, se suponía, transitó el hombre americano procedente de Asia y, antes, de África y, mucho antes, del mar. El hombre americano llegó 
a ese lugar hace unos quince mil años y se ubicó en una posición privilegiada: una montaña de hielo desde donde podía observar si pasaba alguien por ahí, rumbo a lo que más tarde se llamaría América, que por entonces se conocía como el continente Pelásgico o Sin nombre. No vio a nadie pasar en esta dirección, pero sí avistó a lo lejos, muy a lo lejos, una horda de kirguises que marchaba de Sur a Norte. Tras dos mil años de espera vio pasar una familia de mamuts, en dirección Este-Oeste. "¡Vaya, son de casa!", se dijo mientras esbozaba una sonrisa de apariencia coreana $\mathrm{o}$, tal vez, bosquimano-basarawa. Y añadió para sus adentros: "Así que éstos son de donde vengo". Más tarde presenció el paso de una familia de caribúes que marchaban en el mismo sentido $\mathrm{y}$, a lo lejos, un tigre dientes de sable que la acechaba. "Curioso. También son de casa", dijo a alguno de sus hijos, que anotó en su memoria: "Vienen de chez nous". Estuvo ahí hasta el momento en que se empezó a crear, en otras latitudes, lo que sería Mesopotamia, hace unos siete mil años. Cansado de esperar que pasara por ahí alguien más, tomó el camino de América por lo que prefiguraba Alaska, en donde se topó con hombres vestidos de focas o de osos polares que, es verdad, no vio llegar al continente americano por el estrecho de Bering, pero lo cierto es que estaban ahí porque se podían ver, y eran testigos oculares del hecho su mujer, sus hijos, sus nietos, aun sus bisnietos y generaciones de choznos. De Alaska pasó a lo que más tarde sería Canadá, en donde no vio tipis, pero sí alces en celo y lobos que aún no aprendían a aullar. Más adelante contempló el espectáculo de unas montañas rocosas cuyos flancos le sugirieron rostros hieráticos de personajes para él desconocidos. "Me imagino", se dijo, "que algún día esculpirán aquí los rostros de una promesa incumplida. Recorrió grandes planicies habitadas por manadas de millares de bisontes lanudos. Caminando siempre hacia el Sur llegó a unas cuevas en donde se vio a sí mismo pintando, miles años atrás, bisontes derribados por largas varas que parecían lanzas y, a su lado, hombres en posición horizontal con rostros de pájaro, cuyo sexo presentaba una erección.

Un día, cuando estaba a punto de ser calcinado por el sol, llegó a un oasis que no era una auténtica quimera, sino un pequeño edén con 
fuentes de agua pura y dura, muy dura. En el manantial saciaban su sed pequeños hombres robustos provistos de ceño fruncido, rudimentarias vestimentas, arcos, flechas y cuchillos de pedernal.

Más tarde casi perdió la respiración al toparse con gigantescos hombres petrificados que no se dignaron dirigirle una mirada desde sus alturas. Atisbaban al Sur, como señalándole el camino, que siguió.

Cuando la vegetación hubo cambiado transitó por las riberas de grandes lagos, uno de los cuales era de repugnante agua salada. Después el follaje se hizo más espeso y el calor se volvió abrumador. Descubrió entonces, en un boscoso paraje sólo habitado por enormes ceibas, unas monumentales cabezas de piedra con cascos que siglos después llevarían los boxeadores y los ciclistas.

Tras muchos años de travesía llegó a una planicie en donde se levantaban caprichosas construcciones inspiradas en la figura geométrica de la pirámide. Estaban grabadas con signos que no fue capaz de entender, y que nadie entendería después debido a la ausencia de una piedra Rosetta que dijera algo, y a que, mucho más tarde, un perverso fraile, apellidado de Landa, quemaría los códices que informaban acerca de ese pasado y que, tiempo después, pondrían a algunos filólogos rusos a deletrearlos con avidez.

En ese momento de su existencia el hombre americano se puso a reflexionar, sin las pretensiones propias de los filósofos: de algún sitio procedían los seres que habían hecho todo aquello, pero sin lugar a dudas no habían caído del cielo, ni eran descendientes de la famosa pareja de Mesopotamia, cuya existencia se presumía en algunos textos escritos en una curiosa lengua que oscilaba entre el sánscrito y el aymará. Su peregrinar no concluyó ahí porque fue más al Sur, hasta toparse con otras construcciones, también geométricas, pero que no eran, sin embargo, iguales a las que antes lo deslumbraron, y las inscripciones que vio en ellas eran, sin lugar a dudas, tan diferentes como incomprensibles.

El siguiente tramo de su recorrido le pareció interminable porque no había nada en él. Al cabo de los años se encontró al pie de montañas cubiertas de nieve, $\mathrm{y}$ tras perderse en un laberinto de construcciones asentadas sobre grandes piedras cinceladas, subió a una montaña, en donde 
JULIÁN MEZA

seres que le parecieron insólitos se entregaban con fervor al culto del sol, representado por un personaje que escondía su rostro tras una máscara áurea.

Una vez más, decidió desandar su camino y volvió, tras mucho tiempo, al lugar en donde se hallaba el lago salado. Presa del asombro por la belleza del sitio, ahora populoso, se encontró con construcciones geométricas, semejantes a las que antes había visto en otros parajes, y una constelación de canales pestilentes que se abrían paso en torno a una isla.

Se hallaba absorto en la contemplación del lugar cuando vio avanzar por el paso que había entre dos montañas nevadas una caravana de hombres ataviados con ropajes totalmente diferentes a los que llevaban los lugareños. En lugar de taparrabos hechos de tela burda, llevaban cascos, petos o corazas y rodilleras de hierro y montaban animales que avanzaban, como los alces y los lobos, en cuatro patas. En algún momento esos extraños personajes hendieron el silencio con extraños aparatos que producían estallidos y provocaron, como por arte de magia, el pánico y algunos muertos. La extravagancia llegó, lo supo después, a bordo de grandes pájaros alados que en lugar de sobrevolar los mares los hendían. Así confirmó que los hombres de taparrabos eran los dueños del lugar y que los hombres con corazas eran ajenos al sitio. Pese a todo, vio que hubo encuentros pacíficos y celebraciones, pero no duraron mucho porque poco después los hombres de hierro, junto con varios miles de hombres en taparrabo y una mujer enfundada en un traje hecho de tiras de cuero que le recordaba la Coyoxautli pero a la que llamaban María Ribera, atacaron el lugar y provocaron la confusión y la muerte. El hombre americano, que en la barahúnda perdió a casi toda su numerosa familia, tuvo el presentimiento de que su larga vida se acababa, de que todo llegaba a su fin, de que su razón de ser ya no tenía ningún sentido. Y así fue, porque una prolongada historia cedía su lugar a otra, muy distinta. Su estirpe había sido borrada del mapa.

Tras la destrucción y la muerte sembrada por doquier por los hombres con petos de hierro, llegaron unos encapuchados que portaban un extraño símbolo hecho de dos maderos, a los que se hallaba clavada una sangran- 
te figura humana. Luego los encapuchados empezaron a predicar en una extraña lengua que los lugareños no entendían, aunque aquellos creyeron ser entendidos, según quedó asentado en crónicas más tarde escritas por ellos, en donde apuntaron, en términos notariales: "Mientras señalábamos en dirección al cielo decíamos a los hombres en taparrabos: Ahí está Dios. Y estos asentían porque parecían entender qué eran Dios y el cielo. Después les informamos que el personaje clavado a la cruz era un dios y los hombres de taparrabo nos creyeron, aun cuando sus ídolos eran del todo ajenos a nuestra antropomórfica figura". En algo se parecían a ella, pero a fin de cuentas sus rasgos eran vagamente humanos. Algo había de próximo en ellos al hombre incrustado en los maderos, pero se representaban desfigurados, deformados, despedazados, "hendidos por el rayo / y en su mitad podridos".

"No eran del todo humanos porque, a fin de cuentas, eran dioses, y no podían ser iguales a sus humanas criaturas"-reflexionó el hombre americano. Los encapuchados, pertrechados tras las espadas y lanzas metálicas y los arcabuces de los hombres de coraza, creyeron imponer sus creencias a los hombres de taparrabos, pero estos rehusaron someterse a la prédica armada durante generaciones. Los encapuchados decidieron, entonces, aprender las variadas lenguas de los hombres de taparrabos para convencerlos de que vivían en el error y el horror al adorar falsas divinidades, pero fracasaron. No fue sino cuando separaron a los hijos de los padres y convirtieron a aquellos en delatores (prefigurando uno de los métodos utilizados más tarde por el poder soviético en Rusia) que empezaron a imponer sus creencias, ricas en verdades absolutas como la del dios único, que no es único porque tiene un hijo, aun cuando nunca haya conocido mujer, y una paloma, con los que comparte el poder absoluto. Cuando al fin renunciaron al latín y a las numerosas lenguas locales para imponer su confesión y se sirvieron de lo que llamaban castilla, la divinidad del hombre clavado a los maderos se impuso de manera casi absoluta como creencia. Sin embargo, para entonces los convencidos eran apenas poco más de un millón y no los diez o veinte millones que vivían en esas tierras cuando llegaron los hombres con coraza de hierro y encapuchados con creencias del mismo metal. 
JULIÁN MEZA

Poco a poco se edificó ahí una magnífica ciudad en la que coexistieron, pero no convivieron, hombres de diferentes etnias que fueron tipificadas, codificadas y estratificadas. Sometidos por la conquista militar y, luego, espiritual, los autóctonos trabajaron sin descanso para quienes les impusieron la sumisión de diversas maneras, y esto cuando no se trató sencillamente de la esclavitud. Durante siglos se vieron obligados a destruir sus antiguas geometrías y a edificar nuevas y abigarradas edificaciones, en donde el hombre de los maderos presidía nuevos ritos, que ya no eran a cielo abierto sino en interiores, en ocasiones ciertamente descomunales y garigoleados. Poco a poco, los hombres a quienes se cambiaron los taparrabos por calzones de manta empezaron a hablar en esa lengua que se llamaba castilla, y creyeron en el hombre de los maderos, pero como los hijos de los hombres de coraza y de algunos encapuchados no lo creyeron suficientemente poderoso, crearon la imagen de una aindiada divinidad femenina, que aun vestida con ropajes andaluces conquistó a los locales porque era, como la de Monserrat en Cataluña y la de Czestochowa en Polonia, de piel oscura: la Guadalupe.

Los descendientes de los hombres acorazados y encapuchados pronto tuvieron la convicción de que las tierras y las almas conquistadas eran suyas y no de los hombres que, desde lejos, del otro lado del mundo, los gobernaban. Como estos últimos combatieron esta creencia, se produjo, primero, la lucha por obtener beneficios de la empresa que, pese a las prohibiciones, los descendientes de los acorazados y los célibes encapuchados realizaron. El recurso más fácil fue la corrupción-cuenta el hombre americano, que para entonces dudaba de su condición de americano, dado que sabía que ya no era de aquí, ni de allá. Estaba nepanta, como decían los hombres de calzones de manta, porque lo anterior a la presencia de acorazados y encapuchados había sido borrado y en lo de allá hecho aquí no era admitido. Cuando los de allende el océano decidieron poner un límte al ascenso en la jerarquía social, económica, política, religiosa y cultural de los descendientes de acorazados y encapuchados e imponer sus despotismo, se produjo una insumisión de éstos, que tras numerosas y sangrientas batallas, conquistaron el mando 
mediante la proclamación de algo que difusamente llamaron independencia, imaginando que habían hecho algo semejante en lo que se había producido en las colonias inglesas de Norteamérica. A estas alturas el hombre americano ya estaba convencido de que era de aquí y no de allá, y se sumó a las filas de los llamados independentistas, aun cuando no sabía que quería decir la palabra independencia porque no designaba absolutamente nada conocido por él, pues lo mismo habría querido decir "el que ya no depende de los de allá, pero tampoco sabe de quién depende acá", que "el que no sabe de quien depende" o, peor aún,"el que no sabe de quién va a depender ahora", como realmente ocurrió, ocurre y seguirá ocurriendo en tierras del hombre americano.

Hay narradores de ficción que afirman que el hombre americano se volvió independiente debido a la influencia de la ilustración, de la revolución francesa y de la guerra de independencia de los norteamericanos, sin que tengan pruerbas de esto. En su mayoría se trata de fabuladores que ignoran serlo, aunque se consideran objetivos representantes de una ciencia llamada historia, que al hombre americano lo hace reir a carcajadas.

El mundo americano - dice el hombre americano- fue totalmente ajeno a la reforma protestante y, por fortuna, a sus guerras de religión, y permaneció al margen del racionalismo europeo. Más aún: no tuvo nada que ver con la ilustración francesa, inglesa y alemana, y todo parece indicar que el hombre americano no se equivoca, pero es tal el alud de mentiras que sepulta sus convicciones que, según los historiadores del mundo americano, los criollos novohispanos eran brillantes ilustrados que leían en francés sin haber aprendido esta lengua y llevaron a cabo una gesta liberadora que los convirtió en contemporáneos de aquellos que proclamaron los derechos del hombre y del ciudadano mucho antes que la ONU soñara con nacer. La realidad -afirma el hombre americano- es totalmente ajena a las creencias. Después de la llamada guerra de independencia en ese territorio de ultramar de la corona española que se llamaba la Nueva España, y que a partir de de 1821 se llama Estados Unidos Mexicanos por imitación de los Estados Unidos de América, los indios mexicanos siguieron siendo -enfatiza 
el hombre americano- indios y, peor aún, sus condiciones de vida no fueron mejores de aquellas que les impusieron los hombres acorazados y los encapuchados a partir de 1521 .

Los inicios del siglo XIX, cuando los novohispanos decidieron renunciar a ser españoles de segunda clase, son una auténtica delicia-escribe el hombre americano-, pero sólo para los americanos que dicen descender de aquellos a quienes sus antepasados aniquilaron o convirtieron en esclavos: los llamados -debido al equívoco de Cristobal Colón- indios.

Es comprensible que el criollo hispanoamericano odie al peninsular que lo considera español de segunda clase y se rebele contra su dominación, pero lo que resulta por lo menos increíble es que se crea descendiente de aquellos a los que sus propios antepasados asesinaron y dominaron por espacio de trescientos años, estableciendo formas de servidumbre que permanecen y que resultarían escandalosas ya no para un finlandés de hoy, sino aun para un agricultor canadiense del siglo XIX. Quien crea-dice el hombre americano- que la servidumbre impuesta en tierras de la Nueva España en el siglo XVI es cosa del pasado es, en el mejor de los casos, un ignorante y un infame, y no sabe, además, que el trabajo manual de un mexicano del siglo XXI es "mano de obra barata" (eufemismo de esclava) y el de un intelectual es gratuito, a menos que esté adherido al presupuesto oficial. Cuando un mexicano dicta una conferencia en una universidad le pagan con un simpático diploma y, si acaso, le dan las gracias. El trabajo intelectual es, en el mejor de los casos, una decoración estética carente de valor, un adorno en la mesa de los poderosos.

La continuación de la Nueva España en el siglo XIX, llamada México independiente, no sólo reconduce el horror, sino que lo acentúa. Prevalecen el autoritarismo federalista y centralista, un liberalismo ajeno al liberalismo y caracterizado por la ruindad, el militarismo, un civilismo que no tiene nada de cívico, un conservadurismo religioso propio del siglo XVI, es decir, del siglo en que se inicia la implacable Inquisición, que no precisó de los servicios de su actual apóstol, el papa Ratzinger -nos dice el hombre americano. 
Fue un siglo carnavalesco en el que hubo de todo. Lo inauguró un emperador de pacotilla. Vinieron a continuación gobiernos que, dada su falta de legitimidad, se limitaron a buscar el reconocimiento de las potencias de la época y a pedir préstamos. Se sucedieron unos a otros con celeridad: iban de golpe de estado en golpe de estado, se refugiaron en dictaduras que se proclamaron constitucionales, se declararon demócratas cuando en realidad eran autoritarios. Su más célebre y patético representante fue un humorista involuntario que se hacía llamar Su alteza Serenísima

El hombre americano estaba a punto de suicidarse cuando se produjo un hecho sorprendente. Humillados por los supuestos liberales tras un guerra sin sentido, los conservadores, que vivían en tiempos de Pedro el ermitaño, fueron a Europa en busca de un príncipe europeo que quisiera gobernar México. Napoleón el pequeño les propuso a Maximiliano de Habsburgo y lo aceptaron. Maximiliano puso condiciones: debía ser aceptado por los mexicanos mediante un referéndum. Los conservadores recaudaron firmas y lo invitaron a ser emperador de México. No sabían que este príncipe católico no era lo que ellos creían. Al llegar a México, Maximiliano sorprendió a los conservadores porque era un príncipe más liberal que todos los mexicanos liberales juntos. El emperador le propuso a Juárez ser su primer ministro. Por supuesto que el pastorcito del rebaño mexicano no aceptó. Era muy digno. Para que Maximiliano pudiera gobernar México precisó de los servicios de un ejército francés puesto a su disposición por el petit Napoléon. Victor Hugo envió una carta de apoyo a Juárez, pero no por estar en contra de Maximiliano, sino del petit. Maximiliano y su mujer, Carlota, produjeron muchas sorpresas en México. El emperador refrendó capítulos de Las leyes de Reforma que pusieron en su contra a los conservadores. Algo en sus nupcias con los conservadores había fallado, obviamente debido a la ignorancia de éstos, pues tal vez imaginaban a todos los príncipes europeos contemporáneos de Carlomagno, cuando para entonces Austro-Hungría era un imperio en donde prevalecían la tolerancia religiosa, étnica y lingüística, que Maximiliano decidió traer a México. En una carta de la emperatriz Carlota a la emperatriz Eugenia de Monti- 
jo - esposa de Napoleón tercero- le decía, no sin sorpresa, que los mexicanos llamaban indios a los campesinos. Y así les siguieron llamando liberales, porfiristas, maderistas, revolucionarios, priístas, modernizadores antimodernos y panistas. El campesino seguirá siendo indio en México hasta que desaparezca, y no está lejano el día en que se extinga - dice el hombre americano con expresión de tristeza.

Nunca ha habido un gobernante mexicano que realmente se haya ocupado de México de manera tan comprometida como Maximiliano y su esposa, Carlota -rememora el hombre americano. Esta conoció el país mejor que cualquier liberal mexicano del siglo XIX. Discípula de Humboldt, trajo a México árboles y plantas que se adaptaron perfectamente al clima del altiplano. La emperatriz era vista por los indios de la meseta central como una encarnación de la virgen de Guadalupe, aun cuando no era morena.

Debido a la inminencia de la guerra franco-prusiana y a las presiones de los USA, el pequeño Napoleón retiró sus ejércitos y dejó solo a Maximiliano. Únicamente se mantuvieron a su lado dos conservadores mexicanos que son considerados por la historia oficial traidores a la patria: Miramón y Mejía. En realidad, fueron de los pocos mexicanos que entendieron el proyecto de país de Maximiliano. Al frente de un reducido ejército, Maximiliano no fue derrotado, sino capturado y asesinado. Victor Hugo, que había apoyado a Juárez contra Napoleón III, le pidió clemencia para el emperador y le dijo, con toda la lucidez de que era capaz, que pasara a la historia por su clemencia. El oaxaqueño dejó pasar esta opotunidad y fusiló al austriaco. Oficialmente pasó a la historia como el hombre que respetaba el derecho ajeno cuando, en realidad, para entonces ya había despojado a las comunidades indias de sus propiedades y sentado las bases para que la hacienda se convirtiera en latifundio durante el reinado de Porfirio Díaz, el rufián que se maquillaba con polvos de arroz y, de esta manera, le enseñó el camino a Michael Jackson, un cantante de Michoacán, y a Esther Gordilla, una bailarina de rap del Bronx.

El hombre americano declara que ya no entiende nada de lo que pasa y se va al Ajusco a tomar un poco de aire, pero ignora que está por 
venir lo peor, pues ha llegado la república restaurada, que no es república, y tampoco un paso adelante como la reforma Meiji en Japón. A continuación se entroniza en México la dictadura de Díaz, que tiempo después parecerá más progresista que dictadura a los ojos de no pocos historiadores y publicistas que tienen los ojos y el alma puestos en Pinochet y ahora, cada vez más, en Franco.

Contra la dictadura de Díaz se produce un alzamiento al que, pomposamente, se llama revolución. Un antiguo porfirista, Francisco I. Madero, se pronuncia contra el tirano y, amparado en un lema publicitario, "sufragio efectivo, no reelección”, lo obliga a abandonar el país. El héroe del alzamiento es asesinado por un nuevo dictador, patrocinado por los USA: el huichol Victoriano Huerta. Contra éste se unen diversos grupos en armas que dudan, sin embargo, entre derrocarlo o unir fuerzas para combatir a los norteamericanos que, una vez más, invaden México. Finalmente derrotan al nuevo sátrapa y, cada uno por su lado, retoman el camino de las armas. El triunfador, Venustiano Carranza, es un hombre de anteojos y designios oscuros que se proclama jefe constitucionalista y asesina a algunos de sus aliados. Otros, los sonorenses, lo asesinan a él. Ya en la presidencia de la república, Álvaro Obregón y Plutarco Elías Calles asesinan a sus otros aliados, Zapata y Villa, y sientan las bases para entronizar un régimen de partido único, fundado en un control corporativista de la sociedad. Lenin y Mussolini al fin reunidos. Más tarde vendrá el presidente Cárdenas a consolidar ese régimen, que ha prevalecido casi un siglo porque, aun cuando en el año 2000 se produjo lo que parecía un viraje en la historia de México con la derrota del partido único, el PRI, por el el PAN, no fue sino una pirueta porque el sistema corporativo se mantiene intacto hasta hoy. El payaso que llegó así a la presidencia, Vicente Fox, no modificó en nada los andamiajes del sistema político mexicano inventado por el PRI. Ya no hubo partido único, pero quedaron intactos el corporativismo y todos los soportes del antiguo régimen, empezando por la corrupción. El sucesor del primer presidente no prí́sta en casi cien años de historia, Felipe Calderón, ha ido más lejos en el terreno del viejo sistema político: para ser presidente se sirvió de los mecanismos propios del partido único: el apoyo del 
Sindicato de la Educación Nacional, gobernada por una émula de Michael Jackson, y el corporativismo monopólico, encabezado por los oligarcas de la telefonía y la televisión.

A estas alturas de la historia nacional mexicana el hombre mexicano (que ocupó el lugar del hombre americano) ha pensado suicidarse en repetidas ocasiones, pero cree que, al final del túnel, aún queda algo por hacer. Su optimismo es, sin lugar a dudas, desenfrenado. Pero es mera apariencia, porque en realidad lo único que retiene de esta historia es el paso de dos mamuts pasando por el estrecho de Bering en dirección Este-Oeste. Sí, sin lugar a dudas, se trata de una imagen inolvidable, más interesante que el tiempo transcurrido de entonces a nuestros días.

México, octubre de 2010 